\title{
Students' Social and Emotional Competence Promoting Positive Social Relationships and Skills
}

\author{
Reizo Koizumi ${ }^{1, *}$ and Yohei Yamada ${ }^{2}$ \\ ${ }^{1}$ University of Teacher Education Fukuoka, Japan \\ ${ }^{2}$ Baiko Gakuin University, Japan
}

\begin{abstract}
The current study examined causal relationships between social and emotional competence and social relationships and skills in the classroom. Participants were 2,410 third- to ninth-grade students and they responded to the scales of social and emotional competence (SEC), self-esteem, and normative behavior. The classroom teachers rated their normative behavior in the classes. The results indicated that perceived SEC has influences on children's actual normative behavior through self-esteem and perceived normative behavior, and that self-esteem partly mediates the cause-and-effect process between perceived SEC and perceived normative behavior. The same causal structure was found among both elementary school students (third to sixth grades) and junior high school students (seventh to ninth grades), with age-related differences in some path coefficients. The findings support that SEC enhancement by social and emotional learning brings positive outcomes in students' perception and social relationships and skills.
\end{abstract}

Keywords: Social and emotional competence, self-esteem, normative behavior, social and emotional learning, social relationships.

Students' adaptation to school life is one of the key issues for their future life. School teachers are always concerned with students' problem behavior in the classroom as well as their academic achievement. Among a variety of students' maladaptive behavior, one of the teachers' most major concerns in classroom management is misbehavior such as talking out of turn, hindering other students, disobedience, idleness/ slowness, making unnecessary noise, and aggression (Little, 2005). These kinds of behavior are offences against the establishment of rules or social norms in the classroom and cause difficulties in teaching. They significantly interfere with the learning of both other students and the misbehaving students themselves, and teachers spend a considerable amount of time on the behavior management issues to establish social norms in their classes (Clunies-Ross, Little, \& Kienhuis, 2008).

Students' behavior following social norms in the classroom is normative behavior in learning. In a general way, normative behavior has been supposed to develop in a single dimension of heteronomyautonomy from the viewpoints of moral development (Bandura, 1977; Power, Higgins, \& Kohlberg, 1989). The domain theory by Turiel (1983), however, proposes to distinguish between morality and social convention, and it suggests a distinction between the child's developing concepts of these two categories.

*Address correspondence to this author at the University of Teacher Education Fukuoka, 1-1 Akamabunkyo-machi, Munakata, Fukuoka 811-4192, Japan; Tel: +81-940-72-6018; Fax: +81-940-34-1012; E-mail: koizumi@fue.ac.jp, y-yamada@baiko.ac.jp
Morality means issues of human welfare, justice, and rights that reflect inherent features of human society. On the other hand, social conventions refer to practices or attitudes that are expected to do or to have in a society: Examples are ways of greeting such as shaking hands, bowing, and embracing, and calling others by first names or family names. Morality and convention are proposed to be distinct and follow parallel developmental frameworks, though these are mutually related to each other in the actual everyday life (Nucci \& Weber, 1991).

This distinction gives educators insight to classify students' misbehavior into at least two categories; morality-related behavior such as injury, violence, and stealing, and convention-related behavior such as ignoring teacher's instructions, making fun of classmates, and making unnecessary noise in the classes. It is the latter behavior that causes the most concern to teachers, as mentioned above (Little, 2005). If convention-related behavior is controlled to be adaptive in the classroom, classroom climate will become pro-social and more conducive to students' learning.

Efforts to develop students' social and emotional competence (SEC) are reported to promote children's positive relationships with peers as well as classroom teachers (Zins \& Elias, 2006). School-based universal interventions to enhance students' SEC are useful approaches not only to decrease students' maladaptive behavior, but also to establish positive classroom climate (Hahn et al., 2007; Wilson \& Lipsey, 2007). Reporting the effectiveness of these interventions 
based on a meta-analysis of more than 200 programs, however, Durlak, Weissberg, Dymnicki, Taylor, \& Schellinger (2011) recognizes the necessity to examine the presumed mediational role of SEC development in children's adaptive behavior. The present research is concerned to analyze the process of how SEC is related to students' convention-related behavior that follows social norms in the classroom.

The factors that we focus on in this research are children's perceptions. Perception is one of the most essential factors in one's behavior, because recognizing one's own status/condition or awareness of one's ability to do something is strongly related to initiating and maintaining behavior. For example, selfperception (e.g., self-image and self-esteem) plays an important role in promoting students' mental health such as anxiety and depression, and it is reported that social and emotional learning (SEL) programs implementation benefits increases in both students' mental health and self-perception (Banks, 2011; Durlak et al., 2011; Kimber, Sandell, \& Bremberg, 2008). Since SEL programming has been indicated to establish caring learning environment in the classroom (Schaps, Battistich, \& Solomon, 2004), students are supposed to become responsive to teachers and are cooperative with each other. This means they show normative behavior according to rules or social norms in the classroom with self-consciousness of normative behavior, SEC, and properly high self-esteem. The mediational role of these kinds of perception, however, has not been explored yet (Durlak et al., 2011).
This research aims to examine how perceived SEC, self-esteem, and perceived normative behavior result in actual normative behavior in the school. A proposed cause-and-effect relation is that perceived SEC has effects on self-esteem and perceived normative behavior, and these influence actual normative behavior. In this study, two assumed models were tested to examine how SEC and self-esteem are related to perceived normative behavior (see Figure 1): Model (a) is a linear one that self-esteem mediates the process between SEC and perceived normative behavior, and perceived normative behavior influences actual normative behavior; Model (b) contains a double-track route in part that both self-esteem and perceived normative behavior are influenced by SEC, and the next step is similar to Model (a) that perceived normative behavior influences actual normative behavior. In examining the models, developmental differences are also explored if any differences exist in the models between elementary school students and junior high school students.

\section{METHODS}

\section{Participants}

The participants of this study were third- to sixthgrade 1,393 children $(323,372,306$, and 392 , respectively) of 49 classrooms in four public elementary schools, and seventh- to ninth-grade 1,017 children (337, 338, and 342, respectively) of 32 classrooms in two public junior high schools. These
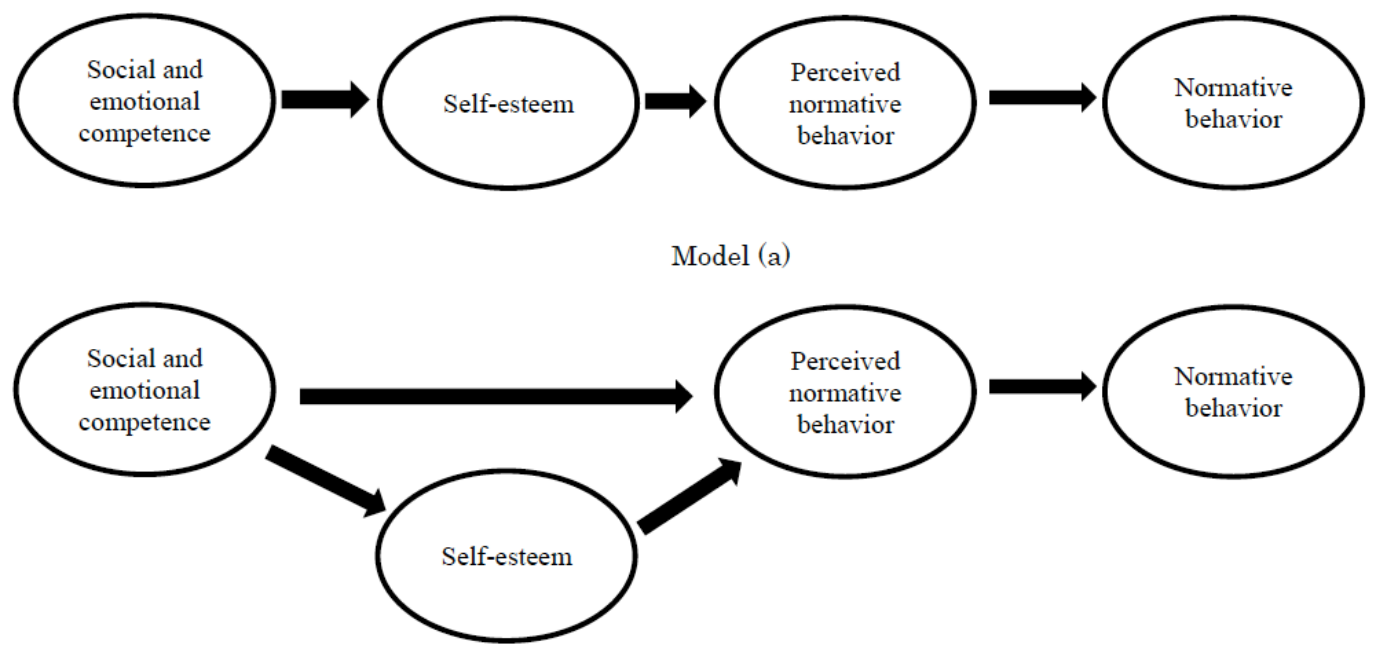

Model (b)

Figure 1: Theoretical competing models of factors influencing normative behavior.

Note: Model (a) shows social and emotional competence has no direct effects on perception of normative behavior and; Model (b) shows social and emotional competence has partly direct effects on perception of normative behavior. 
schools were located in the southern part of Japan and the children came from low to middle socioeconomic groups. Their classroom teachers (49 in the elementary schools and 32 in the junior high schools) also participated in this study to rate the children's behaviors. Female teachers were dominant in the elementary schools, and male teachers in the junior high schools. Their ages ranged from 23 to 60 and the average was 45.5 years old.

\section{Measures}

\section{Perceived SEC}

Emotional Intelligence Test (EIT) (Komatsu \& Hakoda, 2010) was used to measure perceived SEC. This scale is composed of three subscales: recognition of others' emotions, self-control of emotions, and emotional expression. Each subscale has 4 items, and children were required to respond to the 12 items with 4-point scale: 1 (Can't do at all), 2 (Seldom can do), and 3 (Can do sometimes) and 4(Can do always). Three subscale scores were computed by averaging the responses to the items in each subscale: range 1.04.0.

\section{Self-Esteem}

Children's Self-Esteem Scale was composed based on Self-Esteem Inventory in Childhood (SEIC)(Inoue, 1986). Self-Esteem Inventory (Coopersmith, 1967) is a main contributor to develop SEIC. Ten items were selected from SEIC items which showed bigger differences in the item scores between the two groups: $\mathrm{HH}$ (high self-evaluation and high teacher's evaluation of children's self-esteem-related behavior) and LL (low self-evaluation and low teacher's evaluation). Children were required to respond to the 10 items with 4-point scale: 1(Disagree), 2(Partly disagree), and 3(Partly agree) and 4(Agree). Scale scores were computed by averaging the responses to the items: range 1.0-4.0.

\section{Self-Report of Normative Behavior}

Children's perception of their own normative behavior was assessed by Perceived Normative Behavior Scale (PNBS; Yamada, Koizumi, Nakayama, and Miyahara, 2014), a self-report measure comprising three 5-item subscales (Observing Individual Norm, Observing Interpersonal Norm, and Improving Interpersonal Norm), each of which taps a separate dimension of normative behavior. Children were required to respond to the 15 items with 4-point scale: 1(Do not do at all), 2(Do seldom), and 3(Do sometimes) and 4(Do always). Three subscale scores were computed by averaging the responses to the items in each subscale: range 1.0-4.0.

\section{Teacher Report of Normative Behavior}

Four kinds of behavior were selected in a research meeting with two public elementary school teachers and two public junior high school teachers about children's representative and remarkable normative behaviors in the classes: always replying when their name is called, not speaking ill of classmates, being broad-minded about classmates' failures or faults, and cooperating with classmates in the activities decided in the class (e.g., playground activities, preparation for school events). Classroom teachers were required to rate each child for each item with 4-point scale: 1(Do not do at all), 2(Do seldom well), and 3(Do partly well) and 4(Do well). Scale scores of Normative Behavior were computed by averaging the responses to the 4 items: range 1.0-4.0.

\section{Procedure}

Consent for the assessment was obtained from the participants and the school principals, based on Ethical Principles of Japanese Association of Educational Psychology. Self-report measures were administered by the classroom teachers in the regular classroom setting in May or June, the second or third month of the Japanese school year. Teacher rating was completed in July after observing each child's behavior in the school for three months.

\section{RESULTS}

\section{Statistical Analyses}

The hypothesized competing models (see Figure 1) were analyzed via structural equation modeling (SEM) using AMOS 18 (Arbuckle, 2009). The SEM assessed the relative contribution of perceived SEC, self-esteem, self-report of normative behavior to the children's actual normative behavior in the classroom. Two scale scores and six subscale scores were included as manifest variables (see Table $\mathbf{1}$ for means, standard deviations, and correlations). As $X^{2}$ and Goodness fit index (GFI) are sample size dependent, the root mean square error of approximation (RMSEA), the comparative fit index (CFI), and Akaike information criterion (AIC) were used as additional measures of goodness of fit.

Secondary, to examine potential age differences, analyses were conducted using multiple group 
Table 1: Means, Standard Deviations, Cronbache's Alphas, and Correlations of the whole Sample

\begin{tabular}{|c|c|c|c|c|c|c|c|c|}
\hline & 1 & 2 & 3 & 4 & 5 & 6 & 7 & 8 \\
\hline 1. Recognition of others' emotions & - & & & & & & & \\
\hline 2. Self-control of emotions & $.38^{\star *}$ & - & & & & & & \\
\hline 3. Emotional expression & $.63^{* *}$ & $.28^{* *}$ & - & & & & & \\
\hline 4. Self-esteem & $.59^{* *}$ & $.48^{\star *}$ & $.47^{\star *}$ & - & & & & \\
\hline 5. Observing individual norm & $.39^{* *}$ & $.32^{* *}$ & $.26^{* *}$ & $.52^{* *}$ & - & & & \\
\hline 6. Observing interpersonal norm & $.43^{* *}$ & $.39^{* *}$ & $.22^{* *}$ & $.54^{* *}$ & $.54^{* *}$ & - & & \\
\hline 7. Improving interpersonal norm & $.51^{* *}$ & $.31^{* *}$ & $.43^{\star *}$ & $.59^{\star *}$ & $.53^{\star *}$ & $.55^{\star \star}$ & - & \\
\hline 8. Normative behavior (teacher report) & $.14^{* *}$ & $.13^{\star *}$ & $.08^{\star *}$ & $.15^{\star *}$ & $.21^{\star *}$ & $.17^{\star *}$ & $.13^{* *}$ & - \\
\hline Mean & 2.99 & 2.77 & 2.89 & 3.20 & 3.38 & 3.28 & 3.33 & 2.98 \\
\hline Standard Deviation & .58 & .66 & .68 & .49 & .45 & .48 & .44 & .60 \\
\hline Cronbach's alpha & .85 & .85 & .76 & .83 & .70 & .72 & .71 & .77 \\
\hline
\end{tabular}

Note: ${ }^{* *} p<.01$

Table 2: Means, Standard Deviations, Correlations of the Variables by the Kind of School

\begin{tabular}{|c|c|c|c|c|c|c|c|c|}
\hline & 1 & 2 & 3 & 4 & 5 & 6 & 7 & 8 \\
\hline 1. Recognition of others' emotions & - & $.22^{\star *}$ & $.62^{* *}$ & $.52^{\star *}$ & $.35^{\star *}$ & $.41^{* *}$ & $.48^{* *}$ & $.13^{* *}$ \\
\hline 2. Self-control of emotions & $.47^{\star *}$ & - & $.21^{* *}$ & $.37^{* *}$ & $.21^{* *}$ & $.26^{* *}$ & $.19^{* *}$ & -.01 \\
\hline 3. Emotional expression & $.63^{* *}$ & $.33^{* *}$ & - & $.42^{\star *}$ & $.25^{* *}$ & $.19^{* *}$ & $.45^{\star *}$ & $.08^{* *}$ \\
\hline 4. Self-esteem & $.63^{* *}$ & $.54^{\star *}$ & $.51^{* *}$ & - & $.49^{* *}$ & $.48^{\star *}$ & $.56^{\star *}$ & $.09^{* *}$ \\
\hline 5. Observing individual norm & $.41^{* *}$ & $.39^{* *}$ & $.26^{* *}$ & $.54^{* *}$ & - & $.46^{* *}$ & $.46^{* *}$ & $.16^{* *}$ \\
\hline 6. Observing interpersonal norm & $.44^{* *}$ & $.46^{* *}$ & $.23^{* *}$ & $.54^{* *}$ & $.58^{\star *}$ & - & $.52^{* *}$ & $.09^{* *}$ \\
\hline 7. Improving interpersonal norm & $.52^{* *}$ & $.37^{* *}$ & $.42^{* *}$ & $.59^{* *}$ & $.57^{\star \star}$ & $.55^{* *}$ & - & $.08^{* *}$ \\
\hline 8. Normative behavior (teacher report) & $.15^{* *}$ & $.22^{* *}$ & $.08^{* *}$ & $.20^{* *}$ & $.24^{* *}$ & $.23^{* *}$ & $.17^{* *}$ & - \\
\hline Mean (elementary school) & 3.03 & 2.83 & 2.91 & 3.30 & 3.41 & 3.36 & 3.39 & 2.97 \\
\hline $\begin{array}{l}\text { Standard deviation (elementary } \\
\text { school) }\end{array}$ & .62 & 69 & .70 & .51 & .45 & .48 & .44 & .61 \\
\hline Mean (junior high school) & 2.95 & 2.70 & 2.86 & 3.06 & 3.33 & 3.16 & 3.25 & 2.98 \\
\hline Standard deviation (junior high school) & .53 & .61 & .66 & .43 & .43 & .44 & .42 & .58 \\
\hline
\end{tabular}

Note: ${ }^{*} p<.01$ Correlations for elementary school children are reported below the diagonal and correlations for junior high school students are reported above the diagonal.

structural equation modeling (multiple-group SEM) with the kind of school (elementary school/ junior high school) as the grouping variable (see Table 2 for means, standard deviations, and correlations by the kind of schools), which tests whether estimates of model parameters (i.e., path coefficients) vary across groups (Kline, 2005).

\section{Model Evaluation}

In Model (a) the three subscales of perceived emotional intelligence are supposed to have effects on self-esteem, and self-esteem on the three subscales of perceived normative behavior. Among the three subscales of perceived normative behavior, mutual interactions are not permitted in SEM and only one way of influence can be supposed between any two of them. This means that eight patterns are allowed to be tested. Then it was supposed that those three subscales of perceived normative behavior have effects on actual normative behavior. The indices of the best result in Model (a) showed $X 2=204.24$ ( $d f=15$ ), $\mathrm{GFI}=.95, \mathrm{AGFI}=.89, \mathrm{RMSEA}=.11, \mathrm{CFI}=.92, \mathrm{NFI}=.91$, and $\mathrm{AIC}=246.24$.

As for Model (b), the three subscales of perceived emotional intelligence are supposed to have effects on 


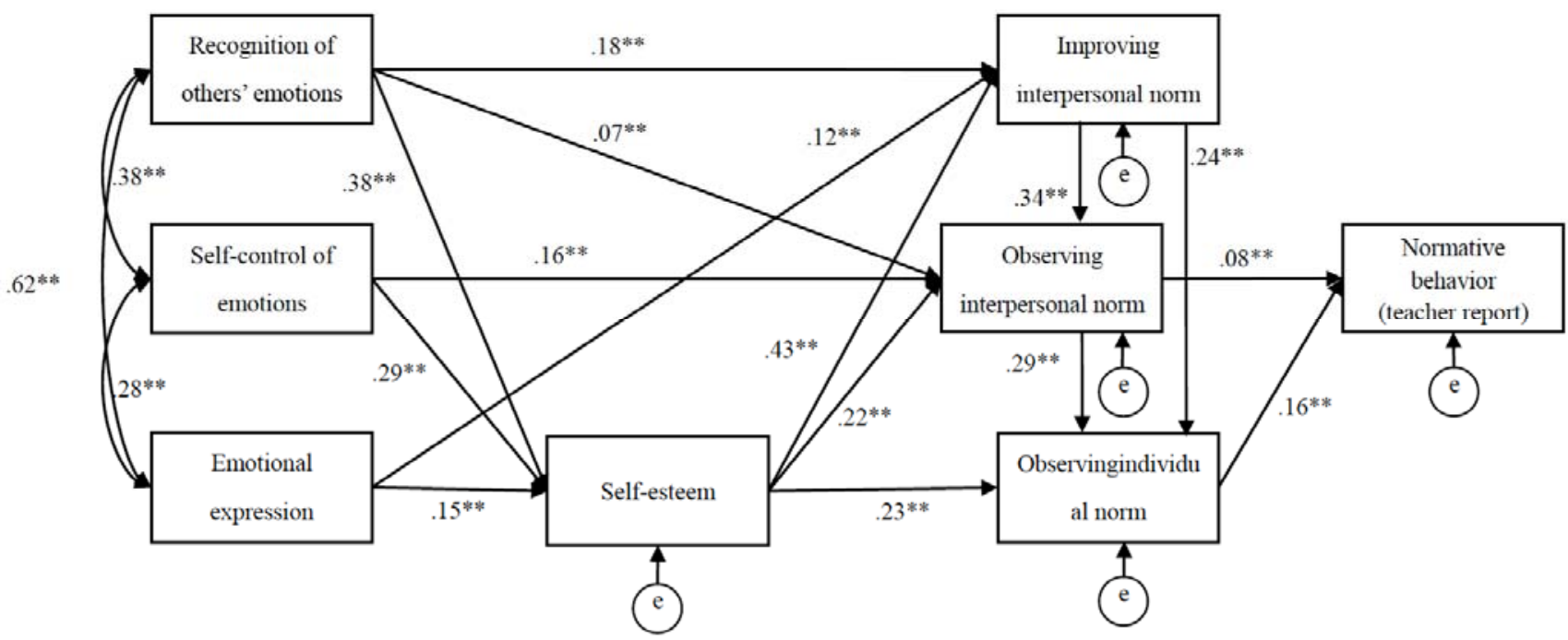

Figure 2: Results of SEM for Model (b).

Note: Non-significant paths are not depicted $(p>=.05) .{ }^{*} p<.05 ;{ }^{* *} p<.01$.

not only self-esteem, but also on the three subscales of perceived normative behavior. All the other paths are supposed in the same way as in Model (a). The indices of the best result in Model (b) were $X^{2}=120.41(d f=10)$, $\mathrm{GFI}=.99, \mathrm{AGFI}=.96, \mathrm{RMSEA}=.07, \mathrm{CFI}=.98, \mathrm{NFI}=.98$, and $\mathrm{AIC}=172.41$ (see Figure 2). This structural model yielded better fit to the data than Model (a), and Model (b) was selected as the cause-and-effect relation.

\section{Comparison of Age Groups}

The next question was whether age differences (elementary school/ junior high school) moderated the relationships among variables in the structural model. We first examined fit indices of Model (b) separately for elementary school $(X 2 \quad(d f=10)=76.91, \quad G F I=.99$, AGFI=.95, $\mathrm{NFI}=.98, \quad \mathrm{CFI}=.99, \quad \mathrm{RMSEA}=.07$, and $A I C=128.91)$ and for junior high school $\left(X^{2}\right.$ $(d f=10)=64.55, \mathrm{GFI}=.99, \mathrm{AGFI}=.95, \mathrm{NFI}=.98, \mathrm{CFI}=.98$, RMSEA $=.07$, and $A I C=116.55)$. The indices showed that Model (b) can be applicable to the both age groups. The following examination of standardized coefficients of each path in the model indicated that six paths should be freely estimated for elementary school and junior high school: from Recognition of others' emotions to Observing Interpersonal Norm $(z=2.48$ : $p<.01)$, from Self-control of emotions to Observing Interpersonal Norm $(z=2.77: p<.01)$, from Emotional expression to Improving Interpersonal Norm $(z=2.22$ : $p<.05)$, from Self-esteem to Observing Individual Norm $(z=2.31: p<.05)$, from Observing Interpersonal Norm to Observing Individual Norm $(z=1.98: p<.05)$, and from Observing Interpersonal Norm to Normative Behavior $(z=2.22: p<.01)$.
In a following multiple group analysis, these six paths were freely estimated and all other paths, covariances, and error variances were constrained: The results of this unconstrained model were $x^{2}$ $(d f=20)=141.46, \mathrm{GFI}=.99, \mathrm{AGFI}=.95$, RMSEA $=.05$, and $A I C=245.46$. This analysis showed a better fit result than the other analysis in which all the paths including the six paths, covariances, and error variances were constrained: The results of the equality constrained model were $\chi^{2}(d f=20)=190.44, \mathrm{GFI}=.98, A G F I=.95$, $\mathrm{RMSEA}=.05, \quad \mathrm{AIC}=294.24)$. The all parameter estimates in the above inequality constrained model for elementary school and junior high school are depicted in Figure 3. Three passes showed higher coefficients for elementary school students than for junior high school students: from Self-control of emotions to Observing Interpersonal Norm, from Observing Interpersonal Norm to Observing Individual Norm, and Observing Interpersonal Norm to Normative Behavior. On the other hand, other three paths showed higher coefficients for junior high school students than for elementary school students: from Recognition of Others' Emotions to Observing Interpersonal Norm, from Emotional expression to Improving Interpersonal Norm, and from Self-esteem to Observing Individual Norm.

\section{DISCUSSION}

\section{Model Evaluation of Normative Behavior}

The aim of this research was to examine how perceived SEC, self-esteem, and perceived normative behavior have influences on students' actual 


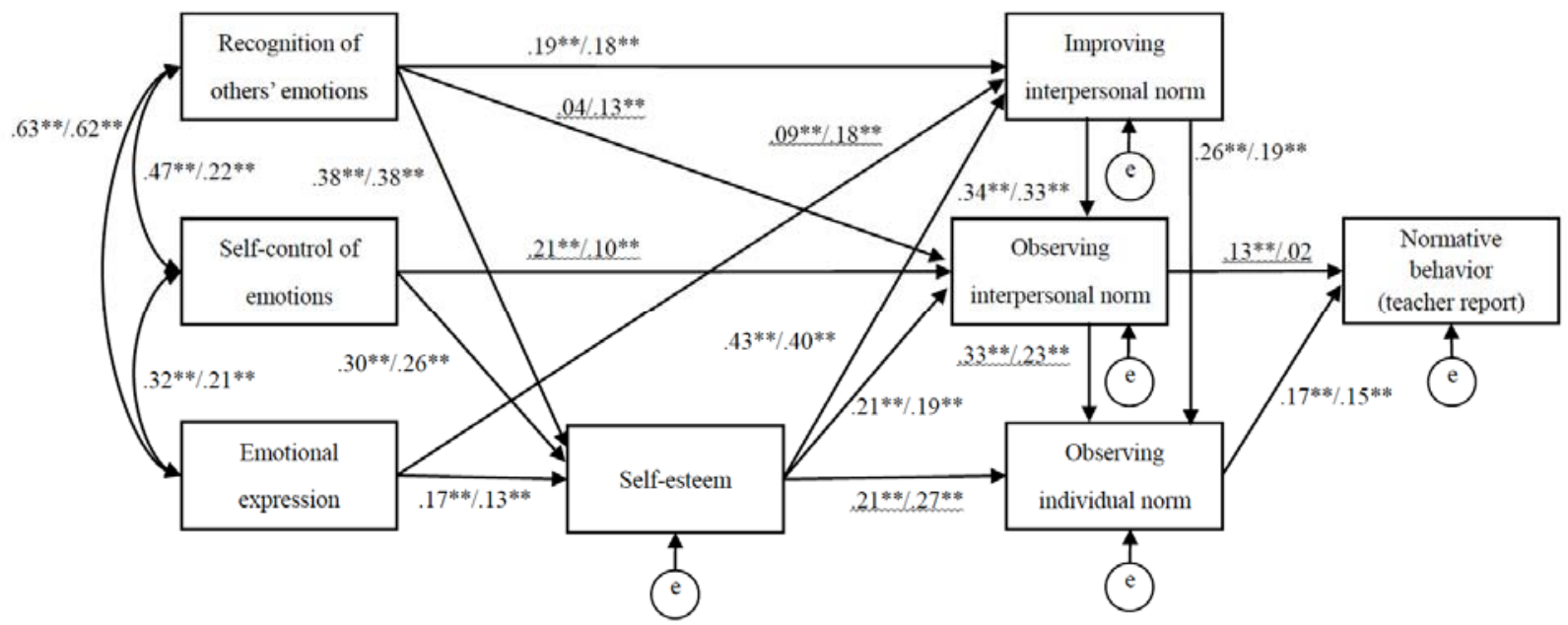

Figure 3: Final model with constraints.

Note: Standardized coefficients presented for elementary school students (before slashes) and junior high school students (after slashes). Underlined paths showed significantly different coefficients between elementary school students and junior high school students $(p<.05) .{ }^{*} p<.05 ;{ }^{* *} p<.01$.

convention-related normative behavior in the class room. The results showed perceived SEC in fact has influences on children's actual normative behavior through self-esteem and perceived normative behavior. Further the comparison of the two supposed models (Model (a) and Model (b)) indicated that self-esteem partly mediates the cause-and-effect process between SEC and perceived normative behavior and that perceived normative behavior influences actual normative behavior as described in Model (b).

These results not only support the previous findings on children's healthy development that SEC skills enhanced by SEL programming promote children's positive attitudes about the self and more adaptive behavior (Catalano et al., 2002; Greenberg et al., 2003; Zins et al., 2004) but also suggest the process how the healthy development is brought about in educational school settings. As depicted in Figure 2, all the three subscales of EIT showed significant positive paths to Self-esteem and then Self-esteem had significant positive influences on all the three subscales of PNBS. EIT subscales also showed some direct positive paths to PNBS subscales. Among the three PNBS subscales cause-and-effect relations were a little complicated, but the two observing-related subscales showed not very strong but significant paths to Normative Behavior. This model indicates that if students' SEC is promoted by school-based SEL programs, it enhances both selfesteem and adaptive and normative behavior in the classroom.

Given that student misbehavior can cause high levels of professional stress and personal distress on school teachers (Miller, 1995), it is convincing that the two observing-related subscales rather than the improving-related subscale of PNBS showed significant paths on teacher report on normative behavior. School teachers are supposed to be more sensitive to children's behavior of observing individual and interpersonal norms than their behavior to improve interpersonal relations. This is because one of the teachers' most major concerns is classroom management, and observing norms in the classroom is essential to keep control over students (Clunies-Ross, Little, \& Kienhuis, 2008).

Each child's normative behavior is expected to have influence on whole-class climate. The finding in this study that SEC is related to desirable norm-related behavior in the individual student level is coincident with the results that whole class climate became more supportive, empowering, and engaging by SEL program implementation (Rivers, Brackett, Reyes, Elbertson, \& Salovey, 2013). Not only with peers but also with classroom teachers, children's positive relationships are reported in the efforts of SEL programming (Zinc \& Elias, 2006: "Purpose" section). The findings including those of the present study indicate that SEC plays a very important role in creating supportive teacher-student and studentstudent relationships in classrooms.

In this study self-esteem was indicated to partly mediate between perceived SEC and perceived normative behavior. In the literature on mental health such as anxiety, depression, and suicide, selfperceptions are key constructs and self-esteem has 
been recognized to account for major amount of mental disorders (Beck, 1967; Evans, Hawton, Rodham, 2004; McGee \& Williams, 2000). The present finding indicates that promoted SEC can contribute to increase and maintain mental health through improved selfesteem. Furthermore, if morality and convention (normative behavior) are proposed to be mutually related to each other in the actual everyday life (Nucci \& Weber, 1991), promoted SEC is expected to decrease morality-related misbehavior such as violence, smoking, and bullying through improved normative behavior. This expectation coincides with the finding that school-based SEL prevented violent behavior (Hahn et al., 2007).

\section{Differences between Age Groups}

Concerning age differences of causal relationships, it was found that the same structure model was applicable for both elementary school students and junior high school students. In the six paths in the model, however, structural equation modeling showed age-related differences in path coefficients. Four paths out of those six paths are related to Observing Interpersonal Norm. For elementary school students this factor of perceived normative behavior mediated more strongly the paths from Self-control of emotions to Normative Behavior than for junior high school students. Since younger students learn how to regulate and manage emotion through socialization practices among the people around them (Lewis \& Michalson, 1983), Observing Interpersonal Norm may be more critical among elementary school-aged students than junior high school-age students. Younger students are first instructed to adjust themselves in the conflicts with others in schools, and Observing Interpersonal Norm may be more essential than the other two factors of normative behavior.

Among junior high school students, on the other hand, one out of the three paths to Improving Interpersonal Norm and also the path from Self-esteem to Observing Individual Norm indicated higher coefficients than those among elementary school students. These results mean that as students grow, relationships among the norm-related factors become more complicated.

The findings on the age differences of causal relationships from perceived SEC to actual normative behavior are coincident with the guideline in Elias et al. (1997) that social and emotional education should be developmentally appropriate and with the actual curriculum contents of many SEL programs. In the preschool to the early elementary grades, differentiation and labeling of negative and positive emotions is included as one of the main subjects in social and emotional education. Upper-grade elementary school students receive instruction in understanding others' emotional reactions, reading social cues, and seeking harmony with others (Elias et al., 1997). Observing Interpersonal Norm is required for these social and emotional skills. When students go on to junior high school, they are directed to wider subject areas such as comparing themselves to others and getting leadership/followership skills (Elias et al., 1997). They are in the stage of identity (Erikson, 1954), and relationships among the norm-related factors that include self-esteem are expect to become more complicated as the results of this study show.

Future studies on causal relationships among SELrelated variables should include academic achievement behavior and actual attainment. Considering wider developmental stages such as preschool and high school is also required. These efforts will clarify a more efficient way in order to develop more effective SEL programs and implement them into standard educational practice.

Focusing on promoting social and emotional competence is essential in children's education to develop their social relationships and cognitive abilities (Durlak et al., 2011). The results obtained in this study not only provide scientific evidence of the cause-andeffect relationships between SEL and educational outcome, but also will enhance paying much more attention than ever to social and emotional competence in educational settings.

\section{REFERENCES}

Arbuckle, J. L. 2009. Amos 18.0 user's guide. United States of America: Amos Development Corporation.

Bandura, A. 1977. Social learning theory. Englewood Cliffs, NJ: Prentice Hall.

Banks, T. 2011. Helping students manage emotions: REBT as a mental health educational curriculum. Educational Psychology in Practice, 27, 383-394. http://dx.doi.org/10.1080/02667363.2011.624303

Beck, A. T. 1967. Depression: Clinical, experimental and theoretical aspects. New York: Harper and Row.

Catalano, R. F., Berglund, M. L., Ryan, J. A. M., Lonczak, H. S., \& Hawkins, J. D. 2004. Positive youth development in the United States: Research findings on evaluations of positive youth development programs. The ANNALS of the American Academy of Political and Social Science, 591, 98-124. http://dx.doi.org/10.1177/0002716203260102

Clunies-Ross, P., Little, E., \& Kienhuis, K. 2008. Self-reported and actual use of proactive and reactive classroom management 
strategies and their relationship with teacher stress and student behavior. Educational Psychology: An International Journal of Experimental Educational Psychology, 28, 693710.

http://dx.doi.org/10.1080/01443410802206700

Coopersmith, S. 1967. The Antecedents of self-esteem. San Francisco: Freeman.

Durlak J.A., Weissberg R.P., Dymnicki A.B., Taylor R.D., \& Schellinger K.B. 2011. The impact of enhancing students' social and emotional learning: a meta-analysis of schoolbased universal interventions. Child Development, 82, 405432. http://dx.doi.org/10.1111/j.1467-8624.2010.01564.x

Elias, M. J., Zins, J. E., Weissberg, R. P., Frey, K., Greenberg, M. T., Haynes, N. M., Kessier, R., Schwab-Stone, M. E., \& Shriver, T. P. 1997. Promoting social and emotional learning: Guidelines for educators. Alexandria, VA: Association for Supervision and Curriculum Development.

Erikson, E.H. 1954. Childhood and Society, 2nd ed. New York: Norton.

Evans, E., Hawton, K., \& Rodham, K. 2004. Factors associated with suicidal phenomena in adolescents: A systematic review of population-based studies. Clinical Psychology Review, 24, 957-979.

http://dx.doi.org/10.1016/i.cpr.2004.04.005

Greenberg, M. T., Weissberg, R. P., O'Brien, M. U., Zins, J. E., Fredericks, L., Resnik, H., et al. 2003. Enhancing Social and Emotional Learning 425 school-based prevention and youth development through coordinated social, emotional, and academic learning. American Psychologist, 58, 466-474. http://dx.doi.org/10.1037/0003-066X.58.6-7.466

Hahn, R., Fuqua-Whitley, D., Wethington, H., Lowy, J., Crosby, A., Fullilove, M., et al. 2007. Effectiveness of universal schoolbased programs to prevent violent and aggressive behavior: A systematic review. American Journal of Preventive Medicine, 33(2, Suppl. 1), S114-S129. http://dx.doi.org/10.1016/j.amepre.2007.04.012

Inoue N. 1986. Relationship between child's self-esteem and response to unsuccessful problems. Japanese Journal of Educational Psychology, 34, 10-19. http://dx.doi.org/10.5926/jiep1953.34.1 10

Kimber, B., Sandell, R., \& Bremberg, S. 2008. Social and emotional raining in Swedish schools for the promotion of mental health: an effectiveness study of 5 years of intervention. Health Education Research, 23, 931-940. http://dx.doi.org/10.1093/her/cyn040

Kline, R. B. 2005. Principles and practice of structural equation modeling (2nd ed.). New York: Guilford.

Komatsu, S., \& Hakoda, Y. 2010. Emotional Intelligence Test. Fukuoka, Japan: Toyo Physical Co.

Lewis, M., \& Michalson, L. 1983. Children's emotions and moods. New York: Plenum Press. http://dx.doi.org/10.1007/978-1-4613-3620-4
Little, E. 2005. Secondary school teachers' perceptions of students' problem behaviours. Educational Psychology, 25, 369-378. http://dx.doi.org/10.1080/01443410500041516

McGee, R., \& Williams, S. 2000. Does low self-esteem predict health compromising behaviors among adolescents? Journal of Adolescence, 23, 569-582. http://dx.doi.org/10.1006/jado.2000.0344

Miller, A. 1995. Teachers' attributions of causality, control and responsibility in respect of difficult pupil behaviour and its successful management. Educational Psychology, 15, 457471. http://dx.doi.org/10.1080/0144341950150408

Nucci, L., \& Weber, E. 1991. The domain approach to values education: From theory to practice. In W. Kurtines \& J. Gewirtz (Eds.), Handbook of moral behavior and development (Volume 3: Applications) (pp. 251-266). Hillsdale, NJ: Lawrence Erlbaum.

Power, F. C., Higgins, A., \& Kohlberg, L. 1989. Lawrence Kohlberg's approach to moral education. New York: Columbia University Press.

Rivers, S. E., Brackett, M. A., Reyes, M. R., Elbertson, N. A., \& Salovey, P. 2013. Improving the social and emotional climate of classrooms: A clustered randomized controlled trial testing the RULER approach. Prevention Science, 14, 77-87. http://dx.doi.org/10.1007/s11121-012-0305-2

Schaps, E., Battistich, V., \& Solomon, D. 2004. Community in schoo as key to student growth: Findings from the Child Development Project. In J. E. Zins, R. P. Weissberg, M. C. Wang, \& H. J. Walberg (Eds.), Building academic success on social and emotional learning: What does the research say? (pp. 189-205). New York: Teachers College Press.

Turiel, E. 1983. The development of social knowledge: Morality \& convention. New York: Cambridge University Press.

Wilson, S. J., \& Lipsey, M. W. 2007. School-based interventions for aggressive and disruptive behavior: Update of a metaanalysis. American Journal of Preventive Medicine, 33(Suppl. 2S), 130-143. http://dx.doi.org/10.1016/j.amepre.2007.04.011

Yamada, Y., Koizumi, R., Nakayama, K., \& Miyahara, N. 2014 Development of Normative Behaviors Scale for elementary and junior high school students. Japanese Journal of Educational Psychology, 61, 387-397. http://dx.doi.org/10.5926/jiep.61.387

Zins, J. E., \& Elias, M. E. 2006. Social and emotional learning. In G. G. Bear \& K. M. Minke (Eds.), Children's needs III (pp. 1-13). Bethesda, MD: National Association of School Psychologists.

Zins, J. E., Weissberg, R. P., Wang, M. C., \& Walberg, H. J. (Eds.). 2004. Building academic success on social and emotional learning: What does the research say? New York: Teachers College Press.

Received on 03-02-2016

Accepted on 08-03-2016

Published on 25-05-2016

DOI: http://dx.doi.org/10.6000/1929-4409.2016.05.10

(C) 2016 Koizumi and Yamada; Licensee Lifescience Global.

This is an open access article licensed under the terms of the Creative Commons Attribution Non-Commercial License (http://creativecommons.org/licenses/by-nc/3.0/) which permits unrestricted, non-commercial use, distribution and reproduction in any medium, provided the work is properly cited. 